\section{Hereditary essential tremor and restless legs syndrome}

Sir

Essential tremor is usually considered to be a monosymptomatic disorder with variable clinical expression, about half of all cases demonstrating an autosomal dominant pattern of inheritance. ${ }^{1}$ Possible associations with other movement disorders have been described, including Parkinson's disease. ${ }^{2}$ We report a patient with hereditary essential tremor and the restless legs syndrome.

A 71-year-old woman complained of a tremor in her right upper limb. This had affected her writing since her teens but had become worse in recent months, also affecting the left arm. The tremor was exacerbated by anxiety and fatigue; alcohol had no relieving effect. Tremulousness of the voice had made it increasingly difficult for her to sing in the church choir. She also complained of discomfort in the legs when sitting, unrelieved by massage but improved by getting up and walking about, and by taking a hot bath. She 'could not relax' because of an uncontrollable urge to move her legs when at rest. Although present throughout the day, this was particularly evident at night and often prevented her from falling asleep. This symptom had also been present since childhood when she had been labelled a 'fidget' at school because of her restlessness in class. A significant exacerbation of these symptoms occurred during pregnancy. Both her father and paternal grandfather had been troubled by a similar tremor of the arms. Moreover, her father had always been 'fidgety' and unable to settle. Her only sibling, a non-identical twin sister, was unaffected, likewise her only son (aged 47).

On examination, the patient had a distal tremor in the upper limbs, accentuated by posture. Writing showed intrusion of tremor and drawing of a spiral was impaired. Head titubation ('no-no') was also evident, and holding a single note revealed vocal tremor. Otherwise neurological examination was entirely normal; in particular, there were no dystonic features nor evidence of a peripheral neuropathy. Investigations (urea, creatinine, thyroid function tests, full blood count, serum vitamin $B_{12}$ and red cell folate) were normal. Treatment with propranolol (40 mg bid) marginally improved her postural tremor, but had no effect on her restless legs.

Clinically this patient had unequivocal hereditary essential tremor. ${ }^{1}$ Furthermore, she fulfilled the suggested diagnostic criteria for restless legs syndrome. ${ }^{3}$ Previous accounts of an association between hereditary essential tremor and restless legs are few. Bornstein reported a pedigree in which restless legs and hereditary tremor coincided in three patients over two generations, with a similar time of onset in each patient, and opined that the syndromes were 'somehow associated'. ${ }^{4}$ Bain et al found restless legs in three of 93 patients with hereditary essential tremor; restless legs and tremor were found to co-segregate. Jankovic has reported encountering several patients with the restless legs syndrome and an essential tremor-like tremor but gives no further details. ${ }^{5}$

The association between essential tremor and restless legs in our patient could be the chance concurrence of two relatively common movement disorders. Alternatively, it may be indicative of an underlying link. The differing pharmacological responsiveness of the two disorders argues against a shared pathophysiological mechanism. A linkage at the genetic level would therefore seem more likely. Like hereditary tremor, restless legs syndrome has been reported to present in childhood and adolescence as an hereditary condition with probable autosomal dominant transmission. It may be that in this family, genes for essential tremor and restless legs have cosegregated. In such families, identification of the genetic locus for one condition may thus facilitate definition of the other.

ANDREW J LARNER CMC ALLEN Department of Neurology, Addenbrooke's Hospital, Cambridge CB2 2QQ, UK

Correspondence to Dr AJ Larner, Department of Neurology, St Mary's Hospital, Praed Street, London W2 1NY, UK

Accepted 21 August 1996

1 Bain PG, Findley LJ, Thompson PD, et al. A study of hereditary essential tremor. Brain 1994 117: 805-24.

2 Lang AE, Kierans C, Blair RDG. Family history of tremor in Parkinson's disease compared with the of controls and patents with idiop with hose of controls and patients with idiopathic dystonia. In: Yahr MD, Bergmann KJ, eds arkinson's disease. Advances in Neurology, vol 45 New York: Raven Press, 1986; pp 313-6.

3 Aldrich MS, Allen R, Ancoli-Isreal S, et al. Toward a better definition of the restless leg syndrome. Mov Disord 1995; 10: 634-42.

4 Bornstein B. Restless legs. Psychiat Neurol (Basel) 1961; 141: 165-201.

5 Jankovic J. Essential tremor and other movement disorders. In: Findley LJ, Koller WC, eds. Handbook of tremor disorders. New York: Marcel Dekker, 1995; pp 245-61.

6 Ekbom KA. Restless legs syndrome. Neurology 1960; 10: 868-73.

\section{Hookworms to treat haemachro- matosis?}

Sir

Biological control strategies can be used to tackle ecological problems and plant diseases. For example, hydrocarbon-metabolizing bacteria are used to degrade oil spills and gardeners use parasitic organisms like the wasp Encarsia formosa, which preys on greenhouse whitefly. However, living organisms are rarely used for treatment of human disease, although Wagner von Janregy won a Nobel prize in 1927 for his work with malaria therapy for syphillis, now superseded by penicillin, and leeches are still valued by plastic surgeons. We should like to propose hookworms for the treatment of haemachromatosis.

Idiopathic haemachromatosis is an autosomal recessive inborn error of iron metabolism with accumulation of $20-40 \mathrm{~g}$ of iron resulting in multi-organ damage and death from cardiac failure or liver disease (normal body iron content is 3-4 g). Removal of excess iron reverses many of the biochemical and functional abnormalities. ${ }^{1}$ Treatment includes weekly venesection of $450 \mathrm{ml}$ of whole blood (equal to $0.2 \mathrm{~g}$ of iron) until iron stores return to normal, which may take two to three years. Although some countries accept haemachromatosis sufferers as paid blood donors, asymptomatic patients in the UK may not perceive any tangible benefit from their weekly hospital visit and are excluded from blood donor panels. ${ }^{2}$ Venesection is inconvenient and noncompliance can be a problem.

Ancylostoma duodenale is a nematode parasite of the human gut. The adult worms are $8-11 \mathrm{~mm}$ long, and attach to the mucosa of the upper small intestine with a set of cutting mouthparts. They live on blood and plasma protein sucked from the lamina propria, each worm consuming $0.2 \mathrm{ml}$ of blood (about $0.09 \mathrm{mg}$ of iron) per day. Worldwide, $700-$ 900 million people harbour hookworms, making this infection second only to menstruation as the major global cause of iron deficiency.

The therapeutic potential of hookworms for haemachromatosis is obvious. To attain a daily blood loss equivalent to $450 \mathrm{ml}$ per week, 300-400 worms would be required, depending on the amount of iron resorbed. $A$ duodenale lives for one to six years and autoinfection does not occur so blood loss is predictable. A three- or six-monthly blood count, albumin and ferritin would be used to monitor therapy. Commonly prescribed drugs would not kill the worms during their residence but once iron stores had returned to normal a two-day course of mebendazole should eradicate them. Hookworms are well adapted and, apart from anaemia, morbidity from natural worm infection is minimal. The practicalities of experimental human infection have been studied previously. ${ }^{3,4}$ Side-effects include pruritus at the site of cutaneous penetration, mild laryngeal and pulmonary symptoms during pulmonary passage and occasionally, upper gastrointestinal discomfort. In the UK there is no danger of transmission to others (except in the special case of miners working in warm damp tunnels) because the soil dwelling stage requires a high ambient temperature. The main problem is likely to be patient consent. There is a natural aversion to the idea of intestinal parasites and blood sucking creatures, and the knowledge that one was harbouring them could colour subsequent perception of abdominal symptoms. For long-term maintenance therapy only a little blood loss is required, so biannual venesection would be used. In conclusion, we feel that despite current enthusiasm for alternative and 'natural' medicine, the possibilities of hookworm therapy for haemachromatosis have been overlooked.

D SIMON C ROSE

Department of Histopathology, University College London, Medical School, Rockefeller Building, University Street, London WC1E 6f7, UK

BEGOÑA A BOVILL Department of Haematology, Whittington Hospital, Highgate Hill, London N19 5NF, UK

\section{Accepted 21 August 1996}

Finlayson NDC. Hereditary (primary) haemachromatosis. BMF 1990; 301: 350-1.

2 Wormwood M, Darke C, Trenchard P. Hereditary haemachromatosis and blood donation. BMF 1991; 302: 593. 
3 Kendrick JF. The length of life and the rate of loss of the hookworms. Ancylostoma duodenale and Necator americanus. Am $\mathcal{F}$ Trop Med 1934; 14: $363-79$.

4 Nawalinski TA, Schad GA. Arrested development in Ancylostoma duodenale: course of a selfinduced infection in man. Am $\mathcal{F}$ Trop Med Hyg induced infection

\section{Obtaining the correct drug history}

Sir

Obtaining an accurate drug history from a patient admitted to hospital requires reliable information sources. These sources include the general practitioner's referral letter, the patient and their medicine bottles, relatives, or carers, and records held by general practitioners or community pharmacists. The accuracy and availability of any of these information sources has been shown to be variable. ${ }^{1}$

An accurate drug history is important to assess any drug-related problems, plan future therapeutic management and avoid potential medicine misadventures. ${ }^{2}$ The ideal situation would be that there are no unintentional differences between the medication prescribed by the general practitioners and that prescribed for the patient on admission to hospital. In view of this we undertook a study to examine the accuracy of drug histories obtained on admission and the type and number of any unintentional differences that occurred.

Eighty consecutive patients who were admitted to three study wards (two care of the elderly and one respiratory medicine) during a three-week period in December 1995 were included. Their mean age was 74 years (range 18-99) and 61 were 65 years or over. A drug history was compiled by the ward pharmacist within 24 hours of admission, using all available information sources and a semi-structured patient interview. This drug history included only the medicines prescribed to be taken regularly. This pharmacist-acquired drug history was compared with the in-patient prescription chart. Data was collected regarding the number of medicines each patient was receiving, and the differences between the pharmacist-acquired drug history and the in-patient prescription chart. The differences were classified as intentional or unintentional. Intention was identified through the medical notes or in discussion with the prescriber. The number and type of unintentional differences were recorded.

The 80 patients in our study were taking 353 medicines (mean 4.4, range $1-12$ ). This appears low for the age group, but only medication to be taken regularly was in cluded, ie, that to be taken when required or purchased over-the-counter was not included. There were 40 unintentional differences identified in 32 patients. Most of the unintentional differences, 21 (53\%) were due to the drug being omitted completely. In six cases $(15 \%)$ the wrong drug was prescribed. The wrong dose was prescribed in eight $(20 \%)$ and the wrong frequency in five $(12 \%)$ cases.

Previous work has shown that information sources available to an admitting doctor may be inaccurate, potentially resulting in incomplete drug histories. ${ }^{3,4}$ The pharmacist-ac- quired drug history is taken later and has been shown to be more complete, due possibly to increased product knowledge and availability of information sources. ${ }^{5}$ In our study, $40 \%$ of patients had at least one unintentional difference between the drug prescribed for them in hospital and those prescribed by their general practitioner. Such inaccuracies can compromise patient care by hindering the identification of drug-related problems and further therapeutic management. Methods to improve drug history taking should involve improving information flow between primary and secondary care, and improving the skills of doctors or pharmacists taking the drug history. The clinical significance of the unintentional differences deserves further study.

RICHARD CATTELL SUE WOOLLER

Department of Pharmacy SINEAD O'MAHONEY

Department of Care for the Elderly Llandough Hospital, Cardiff CF64 2XX, UK

Correspondence to R Cattell, Department of Pharmacy, Royal United Hospital, NHS Trust, Combe Park, Bath BA1 3NG, UK

Accepted 13 September 1996

1 Heerdink ER, Leufkens H, Koppedraaijer C Bakker A. Information on drug use in the elderly: a comparison of pharmacy, general practitioner and patient data. Pharmacy World Sci 1995; 17: $20-4$

2 Gosney M, Tallis R. Prescription of contraindicated and interacting drugs in elderly patients admitted to hospital. Lancet 1984; 2 : 564

3 Holmes GKT, Crisp P, Upton DR. Letters from general practitioners to hospitals. BMF 1984, 284: 497.

4 Gonski PN, Stahters GM, Freiman JS, Smith T. A critical review of admission and discharge medications in the elderly Australian population. Drugs Aging 1993; 3: 358-62.

5 Badowski SA, Rosenbloom P, Dawson PH. Clinical importance of pharmacist-obtained medication histories using a validated questionmedication histories using a validated question
naire. Am $\mathcal{f}$ Hosp Pharm 1984; 41: 731 - 2 .

\section{Incarceration of the penis by a metallic ring}

Sir,

Incarceration or strangulation of the penis by an encircling object is an uncommon clinical event. This paper describes a case of longstanding penile incarceration by a metallic ring and its management.

A 35-year-old man presented in a distressed and embarrassed state with a heavy metal ring (outer diameter $3.2 \mathrm{~cm}$, inner diameter $1.4 \mathrm{~cm}$ ), encircling the penis at its root. The ring had been in place for a month, during which the patient had tried several manoeuvres to remove it, without success, although he was habituated to using a ring in this way. The patient had no urinary complaints. Movement of the ring was not possible and the penis distal to the ring was swollen, ulcerated and harbouring maggots (figure). Attempts to remove the ring using lubricants and by multiple punctures and aspiration of blood from the engorged penis

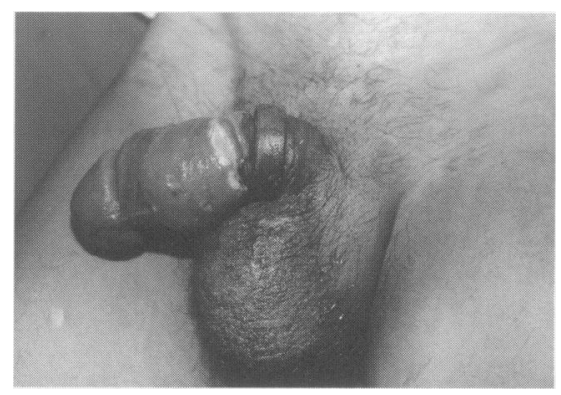

Figure Photograph showing penile incarceration by a metallic ring

failed. Division of the ring was not easy. Under spinal anaesthesia, the distal penis was degloved to the level of cavernous tissue and the iron ring was removed. Subsequent splitthickness skin grafting from the medial side of the right thigh on the denuded penis $(5 \times 3 \mathrm{~cm})$ yielded good results.

A variety of constrictive bands ('cockrings', rubber bands, etc) have been used to increase sexual gratification and prolong erections. ${ }^{1}$ Patients usually present at a late stage when the penis is grossly swollen and attempts to remove the objects have already failed. When these constrictive bands are left in place for too long, the penile skin and shaft becomes oedematous, blood flow is compromised, and rupture of the urethra with extravasation may ensue. Browning et $a l^{2}$ described the use of string to compress the distal penis, making it elongated and narrow. However, other authors have reported 'degloving' the distal penis to the level of cavernous tissue before the foreign object could be removed., ${ }^{3,4}$ inha $^{5}$ suggested that multiple punctures and aspiration of blood from the engorged penis is a simple and safe method and potentially dangerous and mutilating methods of removal of the constricting object should only be used if this treatment fails.

In the present case, penile degloving and subsequent skin grafting did not affect erectile power and the cosmetic appearance was excellent. Even after long-standing penile incarceration, the patient did not have urethral stricture.

PP WASADIKAR SRTB Medical College Ambajogal 431 517, Dist. Beed (Maharashtra),

India

Accepted 2 October 1996

1 McAninch JW. Management of genital skin loss. Urol Clin North Am 1989; 16: 387-97.

2 Browning WH, Reed DC. A method of treatment for incarceration of the penis. F Urol 1969; 101: $189-90$.

3 Tiwari VS, Razdan JL, Yadav VNS. Strangulation of the penis by a metallic nut. Int Surg 1977; 62: $558-60$.

4 Shellhammer P, Donelly J. A mode of treatment for incarceration of the penis. F Trauma 1973; 13: $171-3$.

5 Sinha BB. Penile incarceration by a metallic object. Br f Surg 1988; 75: 33. 